\title{
INVENTARISASI POTENSI DAN BENTUK PEMANENAN HASIL HUTAN KAYU DI DAS TAMI DAN BEWAN DATARAN ARSO KABUPATEN KEEROM
}

\section{(Potential Inventory and Type of Timber Usage from the Forest in Tami and Bewan Watershed Areas of the Arso Plain in Keerom Administrative District)}

\author{
Bernadus Benamen ${ }^{1}$ Wolfram Y. Mofu ${ }^{1 凶}$ dan Piter Gusbager ${ }^{1}$ \\ Jurusan Kehutanan, Fakultas Kehutanan Universitas Papua Manokwari, Papua Barat, \\ 98314. Tlp/Fax: +62986211065 . \\ \enulis Korespondensi: Email: wymofu@gmail.com \\ Diterima: 01 Agust 2018| Disetujui: 29 Agust 2018
}

\begin{abstract}
Abstrak
Penelitian ini bertujuan untuk mengetahui potensi dan bentuk pemanenan hasil hutan kayu di daerah aliran sungai Tami dan Bewan, dataran Arso, Kabupaten Keerom. Metode yang digunakan dalam penelitian ini adalah metode jalur berpetak serta wawancara semistruktural yang didesain guna menggali informasi pemanfaatan hasil hutan kayu serta nilai ekonomisnya. Hasil analisis vegetasi menunjukkan pada wilayah DAS Tami, nilai volume tertinggi untuk tingkat pohon di miliki oleh Pimeleodendron amboinicum dengan volume $13,499 \mathrm{~m}^{3} /$ plot. Sementara untuk tingkat tiang berasal dari jenis Pometia pinnata dengan volume $1,074 \mathrm{~m}^{3} /$ plot. Sementara pada wilayah DAS Bewan, nilai volume tertinggi diperoleh dari jenis Ficus benjamina dengan volume 123,966 m³/plot dan pada tingkat tiang dengan volume tertinggi berasal dari jenis Miristica culcata dengan volume 2,089 $\mathrm{m}^{3} /$ plot. Dalam keseharian masyarakat masih memanfaatkan hasil hutan kayu untuk di jual dan untuk memenuhi kehidupan sehari-hari. Frekuensi pengambilan hasil hutan kayu ratarata 1 minggu sampai 2 bulan tergantung dari kebutuhan/ketersediaan hasil hutan kayu. Upaya konservasi masih dilakukan secara sederhana yaitu ditanam di areal bekas penebangan atau areal kosong.
\end{abstract}

Kata kunci: DAS, struktur dan komposisi, tegakan hutan, pemanfaat kayu, nilai ekonomi.

\begin{abstract}
This study identifies the potency of forest structure and composition around Tami and Bewan watershed areas and economic income that potentially earned from the usage of timber extraction of the Arso plain in Keerom administrative district. The study method lies on a line plot sampling design to approach field data collection and semi-structural question lists for gaining information regarding benefit earned from the forest. From vegetation analysis standpoint, the result indicated that the highest volume at the tree stage of Tami watershed area was Pimeleodendron amboinicum $\left(13.499 \mathrm{~m}^{3} / \mathrm{plot}\right)$. While, at the pole stage, the highest volume was Pometia pinnata $\left(1.074 \mathrm{~m}^{3} /\right.$ plot). Whereas, the highest volume at the tree stage of Bewan watershed area was Ficus benjamina (123.966 $\left.\mathrm{m}^{3} / \mathrm{plot}\right)$. On the flip side, at the pole stage, the highest volume was Miristica culcata $\left(2.089 \mathrm{~m}^{3} / \mathrm{plot}\right)$. In daily life, local communities are still depending their live on the forest, in particular, for timber to purchase daily basic needs. The locals have been frequently accessing timber, but
\end{abstract}


it depends on their necessities. Conservation effort is carried out but in the traditional way by replanting in the cleared land.

Keywords: Watershed, structure and composition, forest standing, timber use, economic value.

\section{PENDAHULUAN}

Hutan merupakan suatu potensi sumberdaya alam yang sangat penting bagi kehidupan manusia. Hutan dipandang sebagai suatu ekosistem dikarenakan hubungan antara masyarakat tumbuh-tumbuhan pembentuk hutan, binatang liar, dan lingkungannya tidak berdiri sendiri, tetapi saling mempengaruhi dan sangat erat kaitannya, serta tidak dapat dipisahkan, hal ini seiring dengan terjadinya penurunan fungsi hutan. Maka pemanfaatan hasil hutan kayu harus dilakukan dengan penuh pertimbangan ekologis dan dengan berpegang pada prinsip pembangunan yang berkelanjutan (Lekitoo et al. 2017).

Pembangunan kehutanan yang berkelanjutan adalah pembangunan yang melestarikan di masa yang akan datang. Hutan juga merupakan bagian yang tidak dapat terpisahkan dalam suatu ekosistem alam yang mempunyai peran sebagai sistem penunjang kehidupan makhluk hidup serta dalam mengatur keadaan udara dan cuaca setempat.

Keerom memiliki potensi sumberdaya hutan yang sangat besar dan umumnya potensi ini belum di ketahui dan di manfaatkan dengan baik. Sebagian besar wilayah ini adalah daerah yang luasnya yaitu mencapai luas 942.157,31 ha (88,04\% dari luas kabupaten) (Badan Pusat Statistik Kabupaten Keerom 2017). Berdasarkan peta kawasan hutan diketahui bahwa Kabupaten Keerom memiliki 5 macam kawasan hutan yang meliputi hutan lindung (HL), hutan produksi (HP), hutan produksi konversi (HPK), hutan produksi terbatas (HPT), dan kawasan suaka alam. Luas keseluruhan kawasan hutan tersebut mencapai 841.857 ha $(71,51 \%$ dari areal berhutan). Berbagai komoditas yang dapat dikembangkan pada sub-sektor kehutanan antara lain meliputi kayu, rotan, dan kulit kayu yang dapat diolah menjadi plywood, blockboard, veneeer, lumber-core, kayu gergajian dan poliyester (Hariyadi 2011). Sektor kehutanan memberikan sumbangan yang sangat besar dalam menunjang pertumbuhan ekonomi daerah dan masyarakat. Pada tahun 2010, subsector kehutanan mampu menyumbang PDRB Kabupaten keerom sebesar 8,53\% dan menempati urutan ketiga dari sektor pertanian (Hariyadi 2011).

Besarnya sumbangan pada tahun 2010 menunjukan bahwa sektor kehutanan memberikan kontribusi yang sangat besar bagi daerah jika dianalisa berdasarkan luas keseluruhan hutan kabupaten keerom, sehingga perlu di lakukan penggelolaan hutan yang lebih optimal. Fakta yang terjadi sekarang menunjukan bahwa masyarakat tidak memanfaatkan hasil hutan dengan baik. Di samping hutan menyediakan beragam kebutuhan bagi masyarakat seperti obat-obatan, makanan, dan kehidupan lainnya, kenyataan di lapangan tidak seperti yang kita pikirkan bahwa masyakat yang ada di dalam dan sekitar hutan masih tergolong miskin. Hal ini menunjukkan bahwa kebijakan pembangunan daerah masih 
salah atau belum berpihak kepada masyarakat.

Berdasarkan peta kawasan hutan dan perairan Kabupaten Keerom, wilayah DAS Tami dan Bewan menurut pembagian fungsi hutan termasuk dalam kawasan areal penggunaan lain (APL). Kawasan ini berfungsi sebagai kawasan untuk berburu, meramu, dan menyediakan kebutuhan perkakas dan obat-obatan, sehingga masyarakat setempat mengenal wilayah ini dengan sebutan segitiga emas karena sebagian besar hutan di dataran Arso telah beralih fungsi menjadi Areal perkebunan kelapa sawit (seperti di tunjukan pada peta). Oleh karena itu, perlu dilakukan suatu penelitian tentang inventarisasi dan pemanenan hasil hutan, guna memberikan informasi serta masukan dalam pengambilan kebijakan untuk pemanfaatan/pengusahaan hutan.

\section{METODE PENELITIAN}

\section{Gambaran Umum Penelitian}

Penelitian ini dilaksanakan di kawasan daerah aliran sungai Tami dan daerah aliran sungai Bewan yang merupakan dua sungai besar di dataran Arso yang termasuk kawasan areal penggunaan lain (APL), dengan luas areal penelitian adalah \pm 6000 Ha. Dalam penelitian ini, digunakan intensitas sampling sebesar $0,3 \%$ guna melihat potensi dan intensitas kawasan. Waktu pelaksanaan penelitian ini berlangsung selama \pm 1 bulan yaitu dari bulan Agustus s/d September tahun 2015. Objek yang diamati dalam penelitian ini adalah jenis vegetasi tingkat tiang dan pohon yang terdapat pada wilayah DAS Tami dan DAS Bewan di dataran Arso, Kabupaten Keerom. Dalam penelitian ini digunakan metode metode garis berpetak dan metode jalur dengan menggunakan pendekatan kualitatif dan pendekatan kuantitatif (Kusmana 1997). Sementara variable yang dikaji dibagi menjadi dua yakni yang meliputi data utama berupa potensi tegakan dan teknik pemanenan. Sementara data penunjang meliputi keadaan umum lokasi penelitian yang diperoleh dari berbagai sumber terkait.

\section{Tahapan Penelitian}

Penelitian dilakukan berdasarkan prosedur berikut:

1. Sebelum mengadakan pengumpulan data, dilakukan pengamatan lapangan meliputi keseluruhan kawasan hutan dengan tujuan melihat secara umum keadaan potensi, tegakan dan kondisi lingkungan lainnya.

2. Pembuatan baseline: Baseline dibuat dekat DAS.

3. Pembuatan titik ikat (penentuan koordinat).

4. Pembuatan jalur: Jalur pengamatan di desain tegak lurus terhadap baseline dengan azimuth $180^{\circ}$ dari arah baseline ke arah hutan.

5. Pembuatan petak pengamatan, pengambilan data vegetasi untuk fase pohon dengan ukuran plot $20 \times 20 \mathrm{~m}$ dan untuk fase tiang dengan ukuran 10 $\times 10 \mathrm{~m}$. Kedua petak pengamatan dibuat di dalam jalur dengan mengacu pada kiri-kanan luas jalur pengamatan masing-masing selebar $10 \mathrm{~m}$.

6. Pengambilan data: pengambilan data dilakukan sesuai dengan jumlah plot yang terbentuk, disesuaikan dengan panjang jalur pengamatan.

a. Pengambilan data awal yaitu pada tingkat pohon dengan ukuran petak $20 \times 20 \mathrm{~m}$, data yang diambil yaitu nama jenis, $\varnothing$ (diameter), TBC 
(tinggi bebas cabang), TT (tinggi total), dan koordinat $\mathrm{x}$ dan $\mathrm{y}$.

b. Pengambilan data pada fase tiang dengan ukuran petak $10 \times 10 \mathrm{~m}$, data yang diambil yaitu nama jenis, $\varnothing$ (diameter), TBC (tinggi bebas cabang), dan TT (tinggi total).

\section{Pengumpulan Data}

Data yang dikumpulkan dalam penelitian ini terbagi menjadi dua, yaitu data primer dan data sekunder. Data primer merupakan data yang diperoleh dengan cara survei langsung dan teknik sampling yang meliputi: diameter dan tinggi pohon. Sedangkan data sekunder terdiri dari jenis-jenis usaha, jumlah usaha, teknik pemanenan, pemilik usaha, mekanisme pemanenan dan pemasaran diperoleh dengan teknik wawancara. Data sekunder adalah data yang diperoleh dari studi pustaka yang meliputi; keadaan fisik, sosial ekonomi, dan keadaan dan kondisi serta status hutan.

\section{Pengolahan Data}

Data hasil penelitian dikumpulkan dan kemudian diolah untuk mendapatkan indeks nilai penting (INP) yang berguna

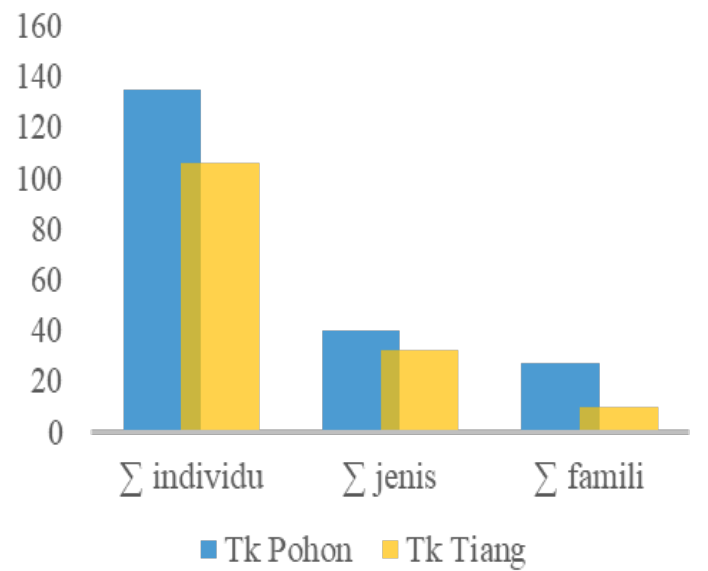

untuk menentukan dominansi suatu jenis terhadap jenis yang lain. Nilai penting diperoleh dari penjumlahan kerapatan relatif, frekuensi relatif, dan dominansi relatif. Untuk mendapatkan nilai-nilai tersebut digunakan rumus perhitungan analisis vegetasi menurut Soerianegara dan Indrawan (1978).

\section{Analisis Data}

Data yang diperoleh dari hasil penelitian selanjutnya akan diolah secara tabulasi dan dianalisis secara deskriptif. Penyajian data dalam bentuk tabel dan gambar.

\section{HASIL DAN PEMBAHASAN}

\section{Jumlah Jenis}

Bratawinata (2001), menjelaskan bahwa komposisi dapat diartikan sebagai suatu susunan dan jumlah jenis yang membentuk tegakan. Dilihat dari hasil inventarisasi hutan dilapangan diperoleh data pada DAS Tami untuk tingkat pohon berjumlah 136 individu yang terdiri dari 40 jenis dan 27 famili dan untuk tingkat tiang diperoleh data 160 individu yang

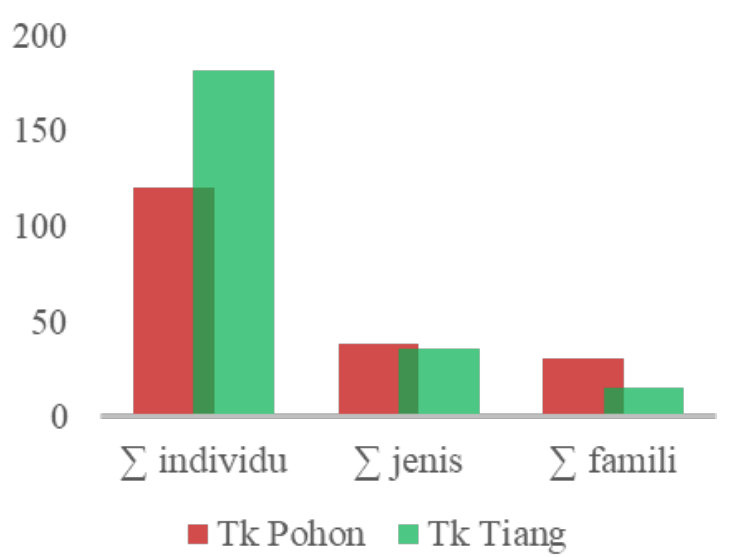

Gambar 1. Jumlah dan struktur vegetasi tegakan hutan pada tingkat pohon dan tiang di daerah aliran sungan (DAS) Tami (Gbr kiri) dan DAS Bewan (Gbr kanan). 
terdiri dari 32 jenis dan 10 famili sedangkan untuk DAS Bewan untuk tingkat pohon diperoleh 120 Individu yang terdiri dari 35 jenis dan 31 famili dan untuk tingkat tiang diperoleh 182 individu yang terdiri dari 36 jenis dan 15 famili. Jumlah jenis untuk tingkat pohon dan tingkat tiang pada DAS Tami dan DAS Bewan dapat dilihat pada Gambar 1.

\section{Potensi DAS Tami}

\section{Tingkat Pohon}

Diketahui bahwa total volume untuk tingkat Pohon adalah 92,372 $\mathrm{m}^{3} /$ plot. Nilai ini diperoleh dari penjumlah volume jenis secara keseluruhan. Untuk lima besar jenis dengan jumlah volume tertinggi di miliki oleh Pimeleodendron amboinicum dengan volume 13,499 $\mathrm{m}^{3} /$ plot. Jenis Pometia Pinnata ditempat kedua dengan volume $10,020 \mathrm{~m}^{3} /$ plot. Ditempat ke tiga adalah jenis Hernandia peltata dengan volume $6,559 \mathrm{~m}^{3} /$ plot. Kemudian Jenis Ficus variegata ditempat ke empat dengan volume $5,949 \mathrm{~m}^{3}$ plot. Sementara di posisi ke lima ditempati oleh jenis Camnosperma macrophylla dengan volume $5,114 \quad \mathrm{~m}^{3} /$ plot. Selanjutnya volume untuk 35 jenis lainnya adalah $51,232 \mathrm{~m}^{3} /$ plot dari keseluruhan total volume $92,373 \mathrm{~m}^{3} /$ plot.

\section{Tingkat Tiang}

Dari hasil perhitungan volume per jenis untuk tingkat tiang pada DAS Tami diperoleh bahwa total volume untuk tingkat tiang adalah $8,657 \mathrm{~m}^{3} /$ plot. Nilai ini diperoleh dari penjumlah volume jenis secara keseluruhan. Dapat dilihat volume tertinggi di miliki oleh Pometia pinnata dengan volume $1,074 \mathrm{~m}^{3} /$ plot. Jenis Pimeleodendron amboinicum ditempat kedua dengan volume $1,025 \mathrm{~m}^{3} / \mathrm{plot}$, ditempat ke tiga adalah jenis Aglaia culculata dengan volume $0,585 \mathrm{~m}^{3} /$ plot.
Kemudian jenis Ficus variegate dengan volume $0,572 \mathrm{~m}^{3} /$ plot, dan posisi ke lima ditempati oleh Canarium hirsutum dengan volume $0.558 \mathrm{~m}^{3} /$ plot. Sementara volume untuk 32 jenis lainnya adalah $4,843 \mathrm{~m}^{3} /$ plot dari keseluruhan total volume $8,657 \mathrm{~m}^{3} /$ plot.

\section{Potensi DAS Bewan}

\section{Tingkat Pohon}

Dari hasil perhitungan volume per jenis untuk tingkat pohon pada DAS Bewan diperoleh data total volume untuk tingkat pohon adalah $311,947 \mathrm{~m}^{3} /$ plot, dimana nilai ini diperoleh dari penjumlah volume jenis secara keseluruhan. Total volume untuk tingkat pohon adalah $311,947 \mathrm{~m}^{3} /$ plot, nilai ini diperoleh dari penjumlah volume jenis secara keseluruhan. dapat dilihat volume tertinggi di miliki oleh Ficus benjamina dengan volume $123,966 \mathrm{~m}^{3} /$ plot. Jenis Pometia pinnata di tempat kedua dengan volume $42,707 \mathrm{~m}^{3} /$ plot. Ditempat ke tiga adalah jenis Pimeleodendron amboinicum dengan volume $30,753 \quad \mathrm{~m}^{3} /$ plot. Kemudian jenis Oktomeles sumatrana di tempat ke empat dengan volume 22,960 $\mathrm{m}^{3} /$ plot, dan di posisi ke lima ditempati oleh jenis Hernandia peltata dengan volume 13,004 $\mathrm{m}^{3} /$ plot. Sementara volume untuk 31 jenis lainnya adalah $220,386 \mathrm{~m}^{3} /$ plot dari keseluruhan total volume $311,947 \mathrm{~m}^{3} /$ plot.

\section{Tingkat Tiang}

Dari hasil perhitungan volume per jenis untuk tingkat tiang pada DAS Bewan diperoleh data bahwa total volume untuk tingkat tiang adalah $8,305 \mathrm{~m} 3 /$ plot, dimana nilai ini diperoleh dari penjumlah volume jenis secara keseluruhan. dapat dilihat bahwa volume tertinggi adalah Miristica culcata dengan volume 2,089 $\mathrm{m}^{3} /$ plot. Jenis Pometia pinnata ditempat 
kedua dengan volume $0,608 \mathrm{~m}^{3} /$ plot, sementara ditempat ke tiga adalah jenis Pimeleodendron amboinicum dengan volume $0,562 \mathrm{~m}^{3} /$ plot. Kemudian jenis Myristica fatua var papuana ditempat ke empat dengan volume $0,436 \mathrm{~m}^{3} / \mathrm{plot}$, dan posisi ke lima ditempati oleh Chisocheton ceramicus dengan volume $0.383 \mathrm{~m}^{3} /$ plot. Selanjutnya volume untuk 31 jenis lainnya adalah 3,695 $\mathrm{m}^{3} /$ plot dari keseluruhan total volume $8,305 \mathrm{~m}^{3} /$ plot. Jika dilihat dari potensi tiang dan pohon pada DAS Tami dan DAS Bewan, jenis yang memiliki volume tertinggi berbeda beda dimana hal ini diduga dipengaruhi oleh variasi luas bidang dasar (LBD) tutupan hutan dan jumlah individu suatu jenis per satuan luas yang beragam.

\section{Bentuk Pemanenan}

\section{Penebangan}

Dari hasil pengamatan responden di lapangan, diperoleh informasi bahwa teknik penebangan pohon diawali dengan penentuan arah rebah pohon. Arah rebah yang benar menurut Juta (1954) dalam Hartono (2008) akan menghasilkan rebahnya pohon sesuai dengan yang diinginkan. Selain itu kecelakaan kerja dan kerusakan lingkungan juga dapat ditekan. Setelah arah rebah ditentukan dilanjutkan dengan membuat takik rebah yang meliputi alas takik dan atap takik. Kemudian membuat takik balas untuk merebahkan pohon. Pembuatan takik rebah diusahakan serendah mungkin. Hal ini dikarenakan dapat mempengaruhi efisiensi proses pemanenan dan pemanfaatan kayu secara keseluruhan. Efisiensi yang dimaksud meliputi produktivitas kerja, pemanfaatan kayu, dan biaya penebangan. Peralatan yang digunakan dalam menebang kayu serta pengangkutan terdiri dari chensaw untuk menebang dan motor atau sepeda untuk mengangkut kayu hasil olahan tersebut.

\section{Pengolahan}

Hasil pengamatan pada responden bahwa ukuran kayu yang dibuat berupa bantalan dan balok dengan ukuran $10 \times$ $20 \mathrm{~cm}$ untuk bantalan dan $20 \times 20 \mathrm{~cm}$ untuk balok. Ukuran kayu tersebut diolah pada saat di dalam hutan dan diangkut keluar ke Tpn. Satu pohon dapat menghasilkan 6 sampai 8 kubik sortimen kayu dengan ukuran yang telah disebutkan di atas. Kayu-kayu tersebut diangkut keluar dari hutan dan dijual pada sawmill-sawmill yang berada di sekitar Kabupaten Keerom maupun di Kabupaten Jayapura. Untuk setiap kayu yang dibawa dan dijual diberi harga sekitar Rp.3.000.000 per $\mathrm{m}^{3}$.

\section{Pengangkutan}

Pengangkutan hasil hutan atau disebut pengangkutan jarak jauh (disebut hauling atau transportation) merupakan tahap terakhir dari kegiatan pemanenan hasil hutan (khususnya yang berupa kayu). Pengangkutan dalam penelitian ini menggunakan motor atau sepeda yang sudah dimodifikasi kesesuaiannya secara khusus untuk mengangkut kayu hasil olahan tersebut. Sepeda atau motor yang dipakai dapat mengangkut 8 bantalan maupun balok dengan komposisi 4 disisi kanan dan 4 disisi kiri. hal ini dibuat agar berat kayu tersebut seimbang dan tidak mudah jatuh. 

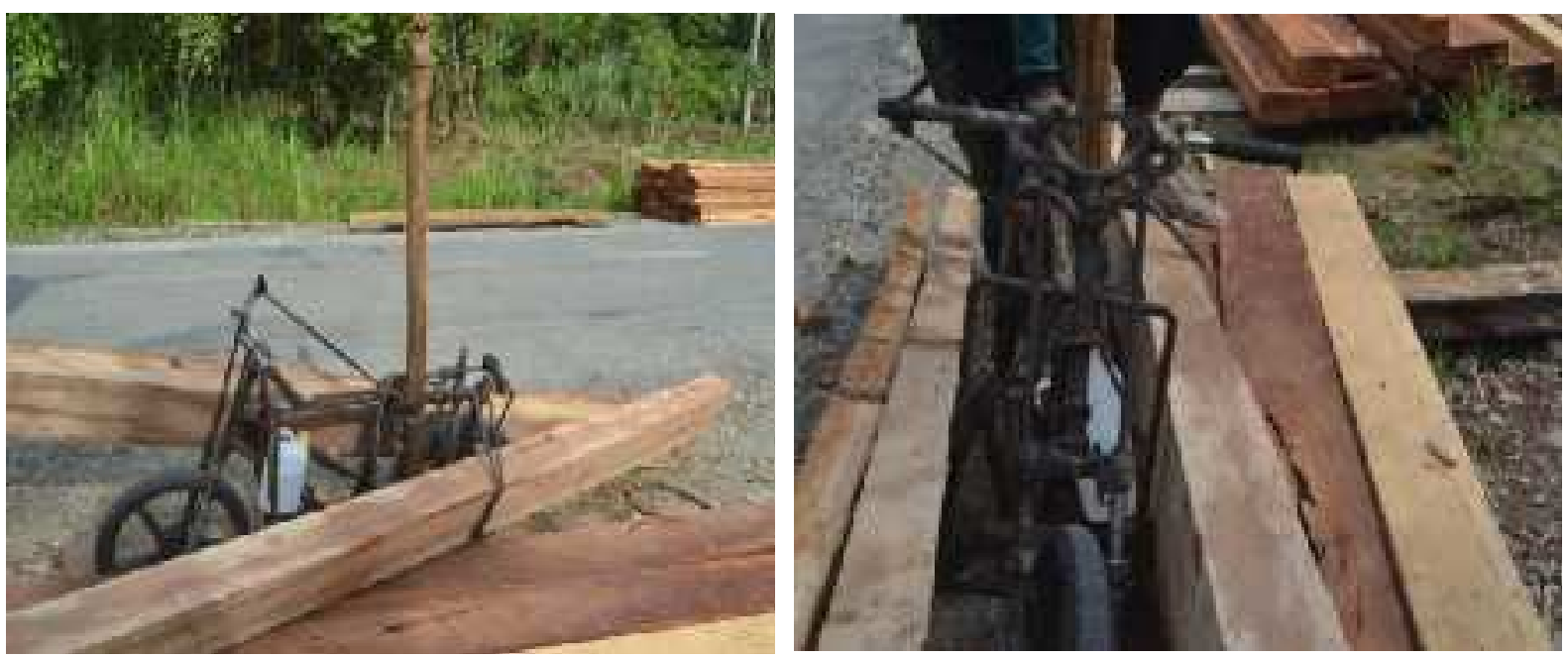

Gambar 2. Pengangkutan sortimen kayu balok menggunakan sepeda.

$\underline{\text { Sistem rel }}$

Sistem rel terdiri dari dua jenis yaitu sistem rel bantalan dan sistem sling: Sistem Rel bantalan adalah sistem jalan atau rute yang terbuat dari bantalan kayu yang sudah tidak mempunyai nilai ekonomi. Sistem rel inilah tempat untuk meletakan alat penggangkut kayu (sepeda dan motor). Namun adakalahnya pengangkutan kayu lewat sistem rel ini tidak menggunakan alat penggangkut tetapi sebagai pengantinya dipakaitnaga manusia yakni dengan cara memikulnya. Sementara sistem sling merupakan sistem yang terbuat dari tali winch, dan papan atau balok penyanggah yang diikatkan pada sling untuk selanjutnya digerakan.

\section{Pendugaan Pendapatan Masyarakat}

Berdasarkan hasil perhitungan pendapatan masyarakat pengelola hutan dengan luasan mencapai 6000 ha, diperoleh hasil sebagai berikut: untuk jenis rimba campuran diperoleh nilai uang sebesar Rp. 605,521,481,040; untuk jenis Pometia pinnata diperoleh nilai uang $\mathrm{Rp}$. 1,033,939,200; dan untuk jenis Intsia bijuga diperoleh nilai uang sebesar Rp. $4,913,848,800$. Nilai tersebut diperoleh dari kubikasi kayu sesuai dengan potensi yang ada pada Kawasan hutan yang kemudian dikalikan dengan harga kayu per kubik sesuai dengan kelompok jenis kayu dimana untuk kelompok jenis kayu rimba campuran harga per kubiknya adalah Rp. 300,000, kelompok jenis kayu Pometia pinnata harga per kubiknya adalah Rp. 400,000 dan kelompok jenis kayu Intsia bijuga Rp. 500,000. Dari hasil tersebut dapat diduga jika masyarakat pengelola hutan mampu mengelola seluruh potensi yang ada pada Kawasan hutan tersebut, maka pendapatan yang diperoleh masyarakat sangat besar. Hal itu dapat menujukkan potensi tingkat kesejahteraan masyarakat tersebut melalui pengelolaan hutan secara lebih baik.

\section{DAFTAR PUSTAKA}

Badan Pusat Statistik Kabupaten Keerom. 2017. Kabupaten Keerom dalam angka. Badan Pusat Statistik

Kabupaten Keerom.


https://keeromkab.bps.go.id/publicatio n/2017/08/16/7949a44b29bd17681028 c429/kabupaten-keerom-dalam-angka2017.html.

Bratawinata A. 2001. Ekologi hutan hujan tropis dan metoda analisis hutan. Departeman Pendidikan Nasional Direktorat Jenderal Pendidikan Tinggi Badan Kerjasama Perguruan Tinggi Indonesia Timur, Makassar.

Hariyadi 2011. Respons daerah dalam pelaksanaan LoI Indonesia - Norwegia tentang kerjasama REDD+ (Studi di Provinsi Papua). Kajian, Vol 16 (2): 331-355.

Hartono AV. 2008. Teknik dan prestasi kerja pemanenan kayu di hutan rakyat
(Studi kasus Kecamatan Cigudeg, Bogor, Jawa Barat). [Skripsi] Bogor: Departemen Hasil Hutan Fakultas Kehutanan Institut Pertanian Bogor.

Kusmana C. 1997. Metode survey vegetasi. Institut Pertanian Bogor.

Lekitoo K, Peday HFZ, Panambe N and Cabuy RL. 2017. Ecological and ethnobotanical facet of 'Kelapa Hutan' (Pandanus spp.) and perspectives towards its existence and benefit. International Journal of Botany, 13: 103-114.

Soerianegara I dan Indrawan. 1978. Ekologi Hutan Indonesia. Fakultas IPB. Bogor. 